\title{
Forum
}

\section{Registrars with research - the right stuff, or the wrong stuff?}

\author{
JoAnNa Bowen, Senior Registrar, St Mary Abbotts Hospital, London W8; and \\ StuART Cox, Psychiatric Registrar, 30 New End Square, London NW3
}

A leading article in the British Medical Journal (Miller, 1992) comprehensively criticised the Joint Planning Advisory Committee (JPAC) for failing to implement the changes in manning levels needed for Achieving a Balance. This leader came as no surprise to psychiatric trainees, and nor did it offer much comfort. The 'bottleneck' between registrar and senior registrar has become a 'log-jam' and although prospects for trainee psychiatrists are not as bleak as for the unfortunate would-be thoracic physicians cited in the leader, they are bad enough. For example, when a single SR post in adult psychiatry was recently advertised for the NW Thames region, there were over 60 enquiries, 45 of which transformed into definite applications, even though the post offered was in a less than popular sub-speciality. Local selection committee members for NW Thames in other psychiatric specialities have also been surprised by the number of applicants. JPAC may not be entirely to blame: the economic recession may be a disincentive for consultants wishing to retire early, thus slowing-up career progression throughout the profession.

In such a competitive environment, it is not surprising that registrars seek to tip the balance of the selector's scales in their favour; and since at least the mid-1980s this has, in effect, meant having publication(s). If the findings of Lewis (1991) and Katona \& Robertson (1993) are applicable everywhere, then the only variable, so far examined, which predicts being short-listed for an SR post is being able to cite one (or more) publication on your $\mathrm{CV}$, and preferably a publication with original data.

What are the implications of this in the mediumto-long-term? One can only applaud the effort of individual trainers (Lewis, 1991), or rotations (Davidson \& Abou-Saleh, 1987) trying to dispel the mystique of research by establishing and fostering special research training, and incidentally improving the selection prospects of their own trainees. However, Lewis is right to point out that registrars exist in a supply and demand environment. Soon the assumption that publication has become the sine qua non of short-listing will filter down to the grass roots of trainees and their tutors, and it will not be long before every candidate for an SR post will cite the "market rate" of two letters and co-authorship of an original research article. When that occurs, either the required standard will need to be raised again (sole author of a review in a prestigious journal?) or possessing publications will no longer "say more about you than a good reference ever can" (Lewis, 1991); nor will the work of the selection committees be any easier.

Selection committees are in the business of trying to pick the best prospect from a range of applicants. What, if any, evidence is there that publication at registrar level correlates with publication or academic performance at either SR or consultant level? Or that it correlates with above average clinical or managerial skill? Or even that it is an indirect indicator of determination, critical ability, and creativity (Lewis, 1991)?

The literature consistently shows that there is a high level of interest in actually doing research among registrar trainees; however, two-thirds find it difficult to find the time (Junaid \& Staines, 1990). Research time has to be "begged, borrowed or stolen" and Bartlett \& Drummond (1992), warning registrars of the difficulty of completing their own clinical trials in time, advise that it is more appropriate for registrars to participate in other people's projects. The main disadvantage of this, however, is that by the time the other authors are ready to publish, the aspiring registrar may already be making the great leap to a first SR post. Flanigan (1992) who reviewed actual publications by registrars in the British Journal of Psychiatry concluded that only case-reports and review articles were realistic options for registrars.

Participation in substantial research projects - far from indicating extra creativity and determination seems to be largely serendipitous; a matter of being in the right place at the right time. The right place and the right time are, of course, being in the right registrar job when the creative gleam in your consultant's eye has gestated to the point where funding or time is available. In an attempt to remove the 
'luck factor' more research supervision, and a closer matching of trainees to possible projects, may be desirable.

No-one who has attempted to do original research doubts that the time required can be surprisingly lengthy. If a registrar is successful in appropriating, by whatever means, (say) one session a week to do his or her own research, what other parts of individual career development might be neglected? How is this session to be balanced against the other skills needed for a broad professional training? Can research comfortably co-exist with an active participation in audit projects? What about learning administrative and management skills? Participation in multidisciplinary team groups? Seeing an individual patient for weekly psychotherapy? And what about the study time for the membership exams?

Clinical commitments in registrar jobs are high. The ability to cite a significant contribution to psychiatric research may say more about you than a good reference can. The danger, however, is that the need to publish research may overwhelm the desire to participate fully in other areas of professional development. Ironically, it seems that, at the moment, we have little idea what power the other indices on a candidate's CV have in predicting their future performance beyond registrar.

In summary, it seems that the drift towards using completed research and publications as the sole selection criteria for short-listing SR applicants may be not only self-defeating in the long-run, but it may also be mistaken in principle. We are certainly not against registrars doing research. The availability and supervision of appropriate research projects for registrars should be one provision of every training scheme; but research should be only one of many provisions of which trainees can, but not must, avail themselves. For this to work in practice, registrars will need to be convinced that selection committees will consider all the aspects of their CV, not only their publications.

\section{References}

Bartlett, A. E. A. \& Drummond, L. M. (1992) The problem with registrar research. Psychiatric Bulletin, 16, 361-362.

Davidson, I. A. \& Abou-SAleh, M. T. (1987) Survey of research activity by trainees in the Mersey region. Psychiatric Bulletin, 11, 94-95.

Flanigan, P. (1992) Junior publications in The British Journal of Psychiatry (Letter). Psychiatric Bulletin, 16, 517-518.

Junaid, O. \& Staines, J. (1990) Career progression in psychiatry: perceptions and realities. Psychiatric Bulletin, $14,484-486$.

KAtona, C. L. E. \& Robertson, M. M. (1993) Who makes it in psychiatry: CV predictors of success in training grades. Psychiatric Bulletin, 127, 27-29.

LEWIS, S. (1991) The right stuff? A prospective controlled trial of trainees' research. Psychiatric Bulletin, 15, 478-480.

Miller, P. (1992) On not achieving a balance. British Medical Journal, 306, 156.

\section{Education and training}

\section{Rumour, myth and reality at SR interviews}

\section{Rex Haigh, Senior Registrar in Psychotherapy, Uffculme Clinic; and Mark Weaver, Registrar in Psychiatry, Uffculme Clinic, Birmingham B13 8QD}

With the current balance of manpower, being appointed to a senior registrar post is seen as more of a hurdle in the NHS career path of junior psychiatrists than the MCRPsych examination. Numerically, it is the most significant bottleneck in the system, with substantially more suitable applicants than available posts. One effect that this has had is to encourage a climate where rumours and myths circulate about what is necessary to become an SR. As well as being stressful and demoralising, this can give candidates the wrong ideas of what is realistically required.

In the last few years, the Bulletin has published articles which offer advice and support to prospective SR candidates (Tufnell, 1984; Margerison, 1987), and more recently Katona \& Robertson (1993) surveyed the CV predictors of success for applicants to training grades in a London teaching hospital. The 'vexed question' of how much research should be expected of registrars has been discussed at the 